Société d'histoire de la révolution de 1848 et des

révolutions du XIXe siècle

$46 \mid 2013$

L'espace du politique en Allemagne au XIX' siècle

\title{
Jacques-Olivier Boudon [dir.], Police et gendarmerie dans l'Empire napoléonien
}

Collection de l'Institut Napoléon, Paris, éditions SPM, 2013, 240 p. ISBN : 978-2-901952-99-2. 22 euros

Natalie Petiteau

\section{CpenEdition}

Édition électronique

URL : http://journals.openedition.org/rh19/4462

DOI : $10.4000 /$ rh 19.4462

ISSN : $1777-5329$

Éditeur

La Société de 1848

Édition imprimée

Date de publication : 1 juin 2013

Pagination : 196-198

ISSN : 1265-1354

\section{Référence électronique}

Natalie Petiteau, « Jacques-Olivier Boudon [dir.], Police et gendarmerie dans l'Empire napoléonien », Revue d'histoire du XIXe siècle [En ligne], 46 | 2013, mis en ligne le 13 janvier 2014, consulté le 22 septembre 2020. URL : http://journals.openedition.org/rh19/4462 ; DOI : https://doi.org/10.4000/rh19.4462

Ce document a été généré automatiquement le 22 septembre 2020.

Tous droits réservés 


\section{Jacques-Olivier Boudon [dir.], Police et gendarmerie dans l'Empire napoléonien}

Collection de l'Institut Napoléon, Paris, éditions SPM, 2013, 240 p. ISBN :

978-2-901952-99-2. 22 euros

\section{Natalie Petiteau}

\section{RÉFÉRENCE}

Jacques-Olivier Boudon [dir.], Police et gendarmerie dans l'Empire napoléonien, collection de l'Institut Napoléon, Paris, éditions SPM, 2013, 240 p. ISBN : 978-2-901952-99-2. 22 euros.

1 Ce volume est le dernier fruit des travaux de l'Institut Napoléon, que Jacques-Olivier Boudon parvient à unir chaque jour un peu mieux à l'Université, puisque cette publication a été faite avec le concours du Centre d'histoire du xix siècle et de l'université Paris-Sorbonne. Il s'inscrit de surcroît dans la lignée des nombreuses recherches actuellement consacrées aux forces du maintien de l'ordre, et qui sont un axe fort du centre de recherche susmentionné. Et c'est parce qu'ils s'inscrivent dans le renouvellement des recherches sur ce sujet que les actes de ce colloque ne reviennent pas sur les figures connues de l'univers policier impérial, mais sur le fonctionnement des rouages de la police et de la gendarmerie.

La publication s'ouvre donc sur un bilan historiographique où Catherine Denys souligne que les récents travaux ont montré l'absence d'unicité de la police d'Ancien Régime, mais aussi les processus de professionnalisation du métier de policier et les pratiques policières réelles. Jean-Noël Luc fait pour sa part le bilan des recherches sur l'héritière de la maréchaussée, recherches qu'il a grandement contribué à stimuler. Sa communication met surtout en évidence tous les thèmes qui attendent encore d'être traités. Elle souligne aussi que l'on en sait désormais beaucoup plus sur la place 
originale de cette institution militaire au sein de l'appareil d'État impérial, sur le rôle de la gendarmerie dans le contrôle des populations, sur la gendarmerie comme agent de l'influence française en Europe.

3 Vient ensuite, sous la plume d'Antoine Boulant, un tableau général de la gendarmerie sous le Consulat et l'Empire, qui rappelle notamment ce que sont les missions préventives et répressives du corps. La police est ensuite présentée par Edouard Ebel, qui analyse le rôle spécifique des commissaires, particulièrement dans la surveillance des espaces urbains et le contrôle des élites locales. Aurélien Lignereux complète ce portrait en étudiant les commissaires de police des départements réunis. Partant d'un corpus de 616 commissaires, majoritairement issus de l'administration, et plus majoritairement encore rivés à leur poste et recrutés localement, il montre que l'Empire a peiné à recruter un personnel qui lui aurait donné toute satisfaction. Pierre Horn analyse le cas spécifique de la Roër, département frontière très surveillé, mais les rivalités entre les agents n'en font pas le département le mieux surveillé. Olivier Accarie, pour sa part, montre ce qu'est le quotidien du travail des commissaires parisiens au début du Consulat, qui ne se contentent pas de réprimer mais qui doivent aussi encadrer, arbitrer, conseiller.

Un autre axe de cette publication porte sur les territoires extérieurs à l'Empire, afin de voir comment les institutions gendarmiques et policières ont été exportées. Gildas Lepetit étudie le cas espagnol qui illustre l'échec du rêve impérial annexionniste. En analysant la contre-insurrection, Michael Broers montre les situations auxquelles les forces de l'ordre ont été affrontées. Nicolas Bourguinat examine pour sa part les insoumissions et le brigandage dans l'Italie centrale et méridionale. La gendarmerie ne peut qu'y jouer un rôle d'appoint à côté des troupes de ligne, tant l'ordre napoléonien y est précaire, tant la mise en application de la conscription fait problème. JacquesOlivier Boudon envisage le cas de la Westphalie, où l'exportation du modèle français a assez bien fonctionné. Mais les incivilités à l'égard de la gendarmerie n'y ont pas manqué et les insurrections de 1809 la mettent à rude épreuve et ouvrent le temps des troubles. Bernard Gainot envisage le cas de l'ordre public dans les colonies. Là aussi les pouvoirs de police se professionnalisent, tandis que prend forme une construction impériale raciale qui vise à maintenir les affranchis dans une condition inférieure. Enfin, Arnaud-Dominique Houte revient sur les Cent Jours de la gendarmerie, qui se rallie aisément à Napoléon et survit tant bien que mal dans cette tourmente. Paradoxalement, si la période s'achève par une remise en cause de la gendarmerie, elle a aussi contribué à ancrer l'institution, précisément parce qu'elle survit en se débarrassant finalement de son « héritage bonapartiste ».

$\mathrm{Au}$ total, cet ouvrage offre un tableau complet et précieux, tout en ouvrant nombre de pistes de recherche à explorer. Il est désormais impossible d'envisager l'histoire du maintien de l'ordre au XIX ${ }^{e}$ siècle sans s'y référer. 